\title{
Un reflejo de lo que somos: reseña de El otro partido: la disputa por el gobierno del fútbol peruano*
}

\author{
Eduardo VillanueVa Mansilla**
}

El fútbol es la más importante de las cosas que no son importantes, decía Carlo Ancelotti, el laureado entrenador italiano. Qué duda cabe: basta comprobar la presencia simbólica del fútbol en nuestra cotidianeidad para comprender cuánto nos importa. La clasificación peruana al Mundial Rusia 2018 fue un acontecimiento mayor, y uno de los resultados de semejante conmoción colectiva fue el libro aquí reseñado, que ofrece un ejercicio de comprensión de la realidad institucional del fútbol peruano, para así entender mejor cómo fue que nos tomó 36 años asistir nuevamente a un Mundial.

Como fenómeno social complejo, el fútbol puede ser estudiado desde una variedad de ángulos muy amplia, incluyendo la dimensión institucional. Finalmente, una actividad con el peso económico y social del fútbol tiene que generar condiciones institucionales para su funcionamiento, y todo sistema institucional bajo control de múltiples actores creará disputas de poder. Más aún, el fútbol tiene alcance nacional e internacional, y depende de relaciones laborales con particularidades específicas, dado que los trabajadores principales no tienen la más larga de las vidas laborales, ni pueden cumplir su tarea sin una serie de actividades complementarias que no generan rentas para el capitalista. En suma, lo institucional es una matriz de conflictos constantes, y esa matriz es la cuestión central del libro: cómo se ha intentado gobernar el fútbol en el Perú, y a su vez, cómo esos intentos de

* Panfichi, A., Vila, G., Chávez, N., Saravia (2018). El otro partido: la disputa por el gobierno del fútbol peruano. Lima: PUCP.

** Departamento de Comunicaciones, Pontificia Universidad Católica del Perú. 
gobierno son reflejos de nuestra propia realidad política y social; cómo las carencias institucionales del fútbol peruano son una expresión específica de las carencias institucionales de nuestro país.

Los autores destacan un término importante: los caballeros. Aquellos que financian el futbol, controlan a los jugadores y deciden por el deporte son "caballeros» en el sentido oligárquico, señorial del uso. Buscan desarrollar capital social y ejercerlo a través de su dedicación al deporte, pero no están dispuestos a ceder el control, ni al interior de los clubes, ni en general. La actividad sigue anclada en prácticas señoriales, arcaicas, que tienen una enorme base cultural, que se encuentran en toda la sociedad peruana. A pesar de que el grueso de los futbolistas - y una cantidad significativa del público del espectáculo en vivo- proviene de los sectores populares, la representación que estos tienen en el deporte es minúscula.

El análisis que se propone parte de revisar el desarrollo institucional del fútbol, marcando tres grandes puntos de inflexión: la Patria Nueva de Leguía, el Gobierno Revolucionario de las Fuerzas Armadas de Velasco, y la transformación neoliberal de Fujimori. En cada caso, se enfrenta la tradición patrimonialista peruana con las fuerzas de cambio, que ciertamente afecta a toda la sociedad peruana. En el fútbol, esa tradición patrimonialista se expresa en la relación condescendiente, con expectativas de servidumbre, entre el «caballero» — es decir, el mecenas o benefactor del equipo de fútbol— y los jugadores; ellos dependen de la buena voluntad del "caballero", quien extiende el favor fundamental de financiar el equipo, sin necesariamente esperar resultados económicos, a cambio de prestigio y posición social. A pesar de los intentos de formalización durante la Patria Nueva, la tradición continúa, sin importar éxitos o fracasos, alrededor de equipos precarios, jugadores sin derechos y campeonatos organizados sin mayor interés por el desarrollo a largo plazo, pues lo que interesa es el resultado inmediato. Mientras en Argentina y Brasil se forjaban instituciones integrales, que podían dar significado a la vida de los socios más allá del fútbol, en el Perú apenas se contaba con relaciones amicales bajo control de los mecenas para poner un equipo en cancha.

El quiebre estructural que plantea el Gobierno Revolucionario de la Fuerza Armada (GRFA) es significativo: no solo el poder oligárquico, gracias al cual se sostiene económicamente la viabilidad del mecenazgo, es profundamente debilitado; la estrategia deportiva cambia, y el gobierno impulsa simultáneamente la recreación y la competencia en otros deportes y la descentralización. Se fuerzan cambios que, como en el resto de la sociedad, terminan por expandir la práctica de fútbol más allá de Lima, y más allá de los mecenazgos. Los intentos iniciales de ampliar la base del fútbol profesional, menores y ocasionales, se consolidan alrededor de la representación de todo el país, aun cuando no hay dinero para el fútbol profesional, y existe una constante presión por éxitos que no va acompañada por el financiamiento que pudo existir antes. 
Como sostienen los autores, la agenda de cambios del GRFA para el fútbol tuvo el mismo efecto que la gran agenda política: logró desmantelar el modelo oligárquico, sin por ello reemplazarlo por un sistema claro y funcional. Ni la Federación Peruana de Fútbol —el ente oficialmente a cargo del deporte en el Perú— ni la Asociación Deportiva de Fútbol Profesional —la reunión de los equipos profesionales - lograron salir del conflicto sobre el carácter mismo del deporte más popular: el manejo de la selección fue un proxy para el gobierno del deporte y de sus potenciales ganancias, en una era en donde los mecenas comenzaban a desaparecer.

El colapso del modelo oligárquico no termina con las conductas señoriales, pero sí impide que se ejerzan con eficacia ante la carencia de base material. El caso deportivo de la década de 1980 es reflejo de ese dilema: luego de la restauración fallida del proyecto pequeño burgués de Fernando Belaunde, el gobierno de Alan García simplemente no encuentra cómo evitar aumentar el caos, y eso se refleja en el fútbol, con campeonatos absurdos y sin fiscalización efectiva. La FPF, todavía bajo control gubernamental, no tiene capacidad de liderazgo, y la ADFP quedó sin representatividad cuando el campeonato profesional llegó a cuarenta equipos, la gran mayoría solo de nombre.

$\mathrm{El}$ «nuevo orden» fujimorista no es un proyecto bien definido, sin duda, pero tiene al menos dos aspectos claros para todo el país y, con ello, para el fútbol: privatizar y reinsertar. El fútbol es dejado de lado como asunto estatal, como todo el deporte, con una liberalización que termina con los «caballeros» casi por completo. Por el lado de la reinserción, el fomento al alineamiento con los modelos globales de gestión lleva a no ofrecer resistencia a la armonización que busca la FIFA, la que promueve la participación en el sistema global a través de la privatización de la gestión política del deporte -impidiendo que los países tengan organizaciones gubernamentales a cargo de la actividad nacional, salvo excepciones precisas- y de sistemas clientelistas efectivos, pues se cuenta con mucho dinero para repartir por todo el mundo.

Aunque el libro no se detiene con mucho detalle en ello, fue la década de 1990 la última en que los caballeros tuvieron algo que disputar. Luego, el desorden descentralizado se enfrentó a la variedad de opciones, desde la gerencia con estilo comercial del Sporting Cristal hasta el «caballero a medias» que llevó a Cienciano a la cumbre solo para olvidarlo un tanto después: Juvenal Silva, el dirigente que condujo al club cusqueño en sus años de gloria, desapareció tan rápido como llegó, y al final, dejó un equipo tan frágil como antes de sus éxitos: el caballero sin los medios de antes aparece apenas como un oportunista.

Casos como estos, que no son discutidos en el libro, apuntan al principal problema: cubrir un siglo de desarrollos institucionales en un texto relativamente corto requiere concentrarse en ciertos aspectos, y al final la discusión se centra en la 
tensión con la FIFA y cómo afecta la gestión del fútbol peruano, ya no solo de los equipos profesionales. Es un tiempo de mayor autonomía, donde el Estado peruano no importa, pero con frustraciones acumuladas que solo se liberan, en algo, con la clasificación al Mundial.

Podría reprocharse a los autores la relativa falta de consistencia en el tratamiento, pero esto se puede explicar por la ya mencionada brevedad, así como por la falta de fuentes y la inexistencia de reflexiones previas de similar alcance; las mismas fuentes periodísticas son bastante débiles, pues el tratamiento del tema por la prensa no fue detallado o consistente sino hasta décadas después del inicio del período cubierto por el libro, y como es evidente, no es posible contar con fuentes orales sobre eventos ocurridos hace casi cien ańos. No tenemos mucho hecho sobre el fútbol, en todo nivel, y este libro sirve como punto de partida para reflexionar sobre lo institucional y el gobierno que sin duda deberán inspirar trabajos más precisos. Cierto descuido en la edición ha permitido varios errores fácticos, contradicciones de menor escala — a veces en la misma página - y reiteraciones innecesarias, en ningún caso descalificadoras, pero sí llamativas (llamar «Wagner» a Jack Warner, por ejemplo). Esto le quita lustre al trabajo, pero no lo hace menos relevante.

Lo que sí queda en claro es que el libro, al conectar la realidad social y política cambiante del país con elementos culturales estructurales que perduran —aunque en contextos de cambio-, nos conecta con el fútbol como una realidad socialmente tan "peruana» como otras cuestiones habitualmente más discutidas en las ciencias sociales. La percepción de la «peruanidad» del fútbol peruano —el desorden, la improvisación, los estados de ánimo súbitamente cambiantes, la desesperanzanos acompaña desde hace décadas: este trabajo nos da evidencia y reflexión para poder afirmar que el fútbol peruano tiene efectivamente una condición similar a la realidad nacional en su conjunto, y de gran pertinencia para entender particularidades, continuidades y procesos que han marcado al Perú desde el inicio del siglo XX. No es más necesaria la intuición: ahora tenemos confirmación. El resultado final, no solo entretenido y conceptualmente útil, sino pertinente para entendernos mejor como país, como sociedad y como aficionados al fútbol, amerita una lectura seria no solo de especialistas, dado que sirve para iniciar sistemáticamente la reflexión sobre el deporte en y desde la institucionalidad peruana. 